\title{
Psychological factors as predictors of early postoperative pain after open nephrectomy
}

This article was published in the following Dove Press journal: Journal of Pain Research

\author{
Ana Mimic' \\ Carsten Bantel2,3 \\ Jelena Jovicic' \\ Branko Mimic ${ }^{4}$ \\ Darija Kisic-Tepavcevic ${ }^{5}$ \\ Otas Durutovic ${ }^{6,7}$ \\ Nebojsa Ladjevic ${ }^{1,7}$ \\ 'Department of Anaesthesia, Urology \\ Clinic, Clinical Centre of Serbia, \\ Belgrade, Serbia; ${ }^{2}$ Department of \\ Anaesthetics, Klinikum Oldenburg \\ AöR, Oldenburg, Germany; ${ }^{3}$ Section of \\ Anaesthetics, Department of Surgery \\ and Cancer, Faculty of Medicine, \\ Imperial College London, London, \\ UK; ${ }^{4}$ East Midlands Congenital \\ Heart Centre, University Hospital \\ Leicester, Leicester, UK; Institute of \\ Epidemiology, School of Medicine, \\ University of Belgrade, Belgrade, \\ Serbia; ' ${ }^{2}$ epartment of Urology, \\ Urology Clinic, Clinical Centre of \\ Serbia, Belgrade, Serbia; ${ }^{7}$ Department \\ of Surgery and Anaesthesiology, \\ School of Medicine, University of \\ Belgrade, Belgrade, Serbia
}

Correspondence: Nebojša Ladjević Urology Clinic, Clinical Centre of Serbia, Resavska 5I, Belgrade I I000, Serbia Tel +38I 63319507

Fax +38I II 36I 7987

Email nladjevic@yahoo.com
Purpose: There is an increasing interest in the identification of predictors for individual responses to analgesics and surgical pain. In this study, we aimed to determine psychological factors that might contribute to this response. We hence investigated patients undergoing a standardized surgical intervention (open nephrectomy).

Patients and methods: Between May 2014 and April 2015, we conducted a prospective observational cohort study. The following psychological tests were administered preoperatively: Mini-Mental State Examination, Amsterdam Preoperative Anxiety and Information Scale (APAIS), Hamilton Anxiety Rating Scale, Hamilton Depression Rating Scale, and Pain Catastrophizing Scale. The primary outcome, postoperative pain intensity (11-point numerical rating scale, [NRS]), was assessed in the "immediate early" (first 8 hours), "early" (12 and 24 hours), and "late early" periods (48 and 72 hours).

Results: A total of 196 patients were assessed, and 150 were finally included in the study. NRS scores improved from 4.9 (95\% confidence interval [CI]: 4.7-5.1) in the "immediate early" to 3.1 (95\% CI: 2.9-3.3) in the "early" and 2.3 (95\% CI: 2.1-2.5) in the "late early" postoperative period. Most (87\%) patients received intravenous opioids, while $13 \%$ received analgesics epidurally. Repeated measures analysis of variance indicated better pain management with epidural analgesia in the first two postoperative periods $(F=15.01, p<0.00)$. Postoperative pain correlated strongly with analgesic strategy and preoperative psychological assessment. Multiple linear regression analysis showed "expected pain" was the only predictor in the "immediate early" phase, and "anxiety" was most important in the "early" postoperative period. In the "late early" phase, catastrophizing was the predominant predictor, alongside "preoperative analgesic usage" and "APAIS anxiety". Conclusion: After open nephrectomy, epidural analgesia conveys a clear advantage for pain management only within the first 24 hours. Moreover, as the psychological phenotype of patients changes distinctively in the first 72 postoperative hours, psychological variables increasingly determine pain intensity, even surpassing employed analgesic strategy as its main predictor.

Keywords: psychological variables, postoperative analgesia, postoperative pain, open nephrectomy, numeric rating scale

\section{Introduction}

Pain is a complex subjective experience with sensory-discriminative, emotionalaffective, and cognitive-evaluative components. ${ }^{1}$ Despite recent advances in understanding and treatment of postsurgical pain, there are still a great number of patients who suffer from moderate to severe pain after operations. ${ }^{2}$

Although pain is an expected part of the postoperative experience, there is considerable inter-individual variation in pain perception even after a standardized surgical 
stimulus. Furthermore, patients undergoing the same procedure may require plasma levels of opioids that sometimes vary more than fivefold to provide satisfying analgesia. ${ }^{3}$ However, the reasons for this variability remain elusive.

In clinical practice, the type of the surgical procedure usually determines the postoperative analgesic strategy. Even though this approach is in keeping with the widely held beliefs, evidence suggests that analgesic strategy should not exclusively be oriented toward the surgical stimulus. According to a prospective cohort study done by Gerbershagen et al, even several common minor- to medium-level surgical interventions resulted in unexpectedly high levels of postoperative pain. ${ }^{4}$

During the past decade, the focus of research in postoperative pain has hence expanded. Now it strives not only to develop new medications and drug delivery systems but it is also increasingly concerned with the identification of predictors of individual responses to analgesics and the pain-inducing trauma. ${ }^{5}$ For instance, a study by Sommer et al investigating 1490 surgical patients who underwent various procedures found preoperative pain, expected pain, surgical fear, and pain catastrophizing as the most important predictors for postoperative pain. ${ }^{2}$ Another important study revealed that young age, preexisting pain, and female sex are predictive factors for severe pain regardless of the type of surgical procedure. ${ }^{6}$

The role of psychological factors for the development of postsurgical pain was also confirmed in a qualitative systematic review by Ip et al. They noted that preoperative pain, anxiety, age, and type of surgery were important independent predictors of postoperative pain and opioid consumption. ${ }^{7}$

Yet, most research about predictors of postoperative pain included inhomogeneous cohorts of patients who underwent a range of different surgical procedures. However, single surgery-based cohorts are not a novelty either. ${ }^{8,9}$ Nevertheless, the majority of these studies were conducted in single sex populations so far such as hysterectomy or breast surgery ${ }^{8,9}$

The aim of the present study was therefore to examine the joint role of demographic factors, previous pain experiences, postoperative analgesia types, and psychological variables as predictors of acute pain during the first 72 postsurgical hours after one single surgical procedure.

In this study, we focused on patients undergoing one standardized surgical intervention to minimize the variability caused by the operation itself. Observed differences in individual postoperative pain responses are therefore more likely the consequences of other variables such as psychological factors.
We chose open nephrectomy here, because it is frequently performed in our hospital. All surgeons follow a standardized approach regardless of the preoperative diagnosis/underlying condition. Additionally, a pilot study revealed the anticipated level of pain is intermediately high enough to yield an appropriate signal that allows meaningful data analysis. Therefore, the results of our study might have practical value in identifying patients at risk. ${ }^{4}$

\section{Patients and methods}

\section{Participants}

This prospective observational cohort study was carried out at the Urology Clinic, Clinical Centre of Serbia, Belgrade, Serbia. The study was approved by The School of Medicine, University of Belgrade, Ethics Committee (No 29/IV-13).

Patients eligible for participation were those scheduled for open nephrectomy between May 2014 and April 2015. A 1 -year observational period was deemed sufficient because it was expected to recruit 150 patients within this time frame.

Excluded were patients undergoing emergency surgery; patients with serious comorbidities (American Society of Anesthesiologists >III); those diagnosed with metastases, known alcohol and drug abuse, and preoperative Mini-Mental State Examination (MMSE) scores less than 25; and patients underwent surgical revision due to major complications, during the same admission.

\section{Study protocol}

During the pre-anesthetic consultation, an anesthetist collected all data concerning patients' demographics (age, gender, height, weight, level of education), medical and surgical history (chronic illnesses, previous interventions, previous renal surgeries), previous pain experience (chronic pain, pain at the surgical site), modifiable risk factors (weight, smoking, alcohol consumption), and use of analgesics 1 month prior to surgery.

Researchers not actively involved in the care of the enrolled patients explained the study protocol and performed the psychological tests. All patients gave written informed consent 1 day prior to surgery.

The following psychological tests were employed in this study:

1. Assessment of the expected level of postoperative pain using an 11-point numerical rating scale (NRS) where 0 represented "no pain" and 10 "worst pain imaginable".

2. MMSE: The MMSE consists of a 30-point questionnaire that is frequently used in clinical and research settings to measure cognitive impairment. ${ }^{10}$ In this study, it was 
used as one of the exclusion criteria since patients with scores less than 25 are less likely to use the other tests appropriately.

3. Amsterdam Preoperative Anxiety and Information Scale (APAIS): APAIS is a widely used self-report questionnaire, comprising six questions that have been specifically developed and validated to evaluate preoperative anxiety and information requirement. ${ }^{11}$ The score is divided into two subcategories that measure anxiety (APAIS ax) and need for information (APAIS inf). The anxiety scale consists of four items, each of which can be scored on a scale from 1 to 5 . The total score of the anxiety scale ranges from 4 to 20 . A value $>11$ has been suggested to be predictive of anxiety, with low likelihood of false-positive results. The need-for-information scale consists of two items, each of which can also be scored from 1 to 5 , so that the test ranges from 2 to 10 . A value $>5$ indicates positive attitude toward receiving information, while score $>8$ indicates very high information requirement (anxiety). ${ }^{11}$

4. Hamilton Anxiety Rating Scale (HAM-A) is one of the first rating scales developed to measure the severity of anxiety symptoms, and it is still widely used. It consists of 14 items, each defined by series of symptoms. The scale measures both psychological anxiety (mental agitation and psychological distress) and somatic anxiety (physical complaints related to anxiety). ${ }^{12}$

5. Hamilton Depression Rating Scale (HAM-D) was used to detect depressive symptoms. ${ }^{13}$ The scale contains 21 questions pertaining to symptoms of depression experienced over the past week. Eight items are scored on a 5-point scale, ranging from $0=$ not present to $4=$ severe and nine are scored from 0 to 2 . A total score of 14-18 indicates moderate depression, a score of 19-22 indicates severe depression, and a score $\geq 23$ indicates very severe depression.

6. The Pain Catastrophizing Scale (PCS), a 13-item tool, was applied to assess catastrophic thinking associated with pain. ${ }^{14}$ The PCS instructions ask participants to reflect on past painful experiences and to rate the degree to which they experienced each of 13 presented thoughts or feelings on 5-point scales with 0 indicating "not at all" and 4 "all the time". The PCS yields a total score and three subscale scores assessing rumination, magnification, and helplessness.

All tests except for the PCS were officially recognized and are widely used in Serbian language for more than three decades. The PCS was validated for Serbian patients, as part of this study. In brief, two native Serbians (an anesthetist and a neuro-psychiatrist) fluent in English translated it from
English to Serbian. Two native English speakers fluent in Serbian who were naïve to the outcome measurement did the backward translation. Pilot testing was done in 15 patients of the target population. Internal consistency evaluation showed a Cronbach's alpha of 0.90 for the rumination subscale, an alpha of 0.91 for the helplessness subscale, an alpha of 0.87 for the magnification subscale, and an alpha of 0.93 for the total PCS scale. These values were similar to what has been published in a study by Osman et al. ${ }^{15}$ The sensitivity and specificity of the PCS in our cohort were $83 \%$ and $78 \%$, respectively.

\section{Anesthesia protocol and postoperative pain management}

All patients were anesthetized according to a standardized protocol: Anesthesia was induced with intravenous (IV) propofol (1-2 mg/kg), fentanyl (100 $\mu \mathrm{g})$, and rocuronium (0.6 $\mathrm{mg} / \mathrm{kg})$. Maintenance of anesthesia was achieved using sevoflurane $(1-2.5 \%)$ in a mixture of either oxygen and nitrous oxide or oxygen and air. Repeated boluses of 50-100 $\mu \mathrm{g}$ IV fentanyl were used for intraoperative analgesia as per the anesthetist's discretion. All patients received IV paracetamol before the end of surgery.

After induction of anesthesia, patients were placed in a lateral position on a flexed operation table. A surgical consultant performed an open nephrectomy through a standardized flank incision that was $15-18 \mathrm{~cm}$ above and in direction of the 11th intercostal space. This was followed by the dissection of the external oblique muscle just above the 12th rib.

Postoperative analgesia was achieved as per departmental guidelines and consisted of either IV or epidural drug administration.

Patients in the IV group received continuous morphine or tramadol infusions for the first 24 hours, followed by 100 mg tramadol every 6 hours during the second and third days.

In the epidural group, a thoracic epidural catheter was placed before induction of anesthesia and patients received a mix of levo-bupivacaine $1.25 \mathrm{mg} / \mathrm{mL}$ and fentanyl $2 \mu \mathrm{g} /$ $\mathrm{mL}$ at a rate of $7-9 \mathrm{~mL} / \mathrm{h}$. Epidural catheters were removed on the second postoperative day before patients were transferred to the ward.

All patients also received regular paracetamol and a morphine bolus as required (rescue analgesia).

\section{Pain intensity assessment}

Expected pain and preoperative as well as postoperative pain intensity was assessed using an 11-point NRS with 0 representing "no pain" and 10 "worst pain imaginable". ${ }^{16,17}$ 
The method of pain assessment was explained to all patients before surgery and was conducted at different time points (1, 2, 3, 4, 8, 12, 16, 24, 48, and 72 hours, respectively) after surgery.

\section{Statistical analysis}

Data were first analyzed descriptively and shown as mean $\pm 95 \%$ confidence interval $(95 \% \mathrm{CI})$, medians, and ranges, as well as frequencies and percentages where appropriate.

Results of postsurgical pain assessments originally done at nine different time points in this study were pooled to then represent three distinct postoperative phases. Phase I ("immediate early period") included NRS scores from hours 1, 2, 3,4 , and 8 , respectively. Phase II ("early period") contained the data from hours 12 and 24, while Phase III ("late early") covered hours 48 and 72 . Each time phase was represented as a mean value of the raw data.

This data reduction strategy was employed to facilitate easier interpretability of results and to prevent overinterpretation in cases where significant results were found only at one time point. It was subsequently employed for all further analysis in this study.

A univariate repeated measure analysis of variance (ANOVA) was used to analyze the changes of pain intensity over time in general and was dependent on the analgesic techniques (IV, epidural) employed.

Next, a nonparametric Spearman's correlation matrix was generated to analyze associations between all 28 assessed variables and the pain intensity in the three postoperative phases.

Finally, a (multiple) linear regression model was used to analyze the predictive value of seven independent variables on postoperative pain intensity. These seven variables were chosen because they were significantly associated with pain in the correlation matrix and displayed rhovalues $>0.2$.

All analyses were done using SPSS 16.0 (SPSS, Chicago, IL, USA). A $p<0.05$ was considered significant throughout the study.

\section{Results}

A total of 196 patients were assessed for eligibility (Figure 1). Forty-one patients were excluded because they met at least one exclusion criterion. Five more patients were excluded during the study due to incomplete documentation. Therefore, a total of 150 patients were finally analyzed.

Data about patients' demographics, comorbidities, preoperative pain assessments, intraoperative management, and results of preoperative psychological tests are shown in Table 1.

There were more male (56\%) than female participants (44\%), and most participants (58\%) were between 41 and 65 years of age. IV opioid administration was the predominant postoperative analgesic strategy and applied in $87 \%(n=131)$ of the cases.

\section{Pain intensity}

Mean pain intensity declined significantly over time in the entire cohort ( $F=88.66, p=0.000$; repeated measures ANOVA) (Figure 2). While it was 4.9 (95\% CI: 4.7-5.1) in the "immediate early" (1 to 8 hours) postoperative period, it was 3.1 (95\% CI: 2.9-3.3) in the "early" (12 to 24 hours) phase and reached its lowest in the "late early" (48 to 72 hours) postoperative period with 2.3 (95\% CI: 2.1-2.5).

Changes in pain intensity in the two analgesic groups (IV or epidural) over time are presented in Figure 3. Repeated measures ANOVA showed pain intensities differed significantly between groups in periods 1 and 2 but not period 3 $(F=15.01, p<0.00)$.

\section{Predictors of postoperative pain}

First, all 28 recorded variables were analyzed for associations with postoperative pain intensity using Spearman's correlation. Eleven variables showed significant correlations in the

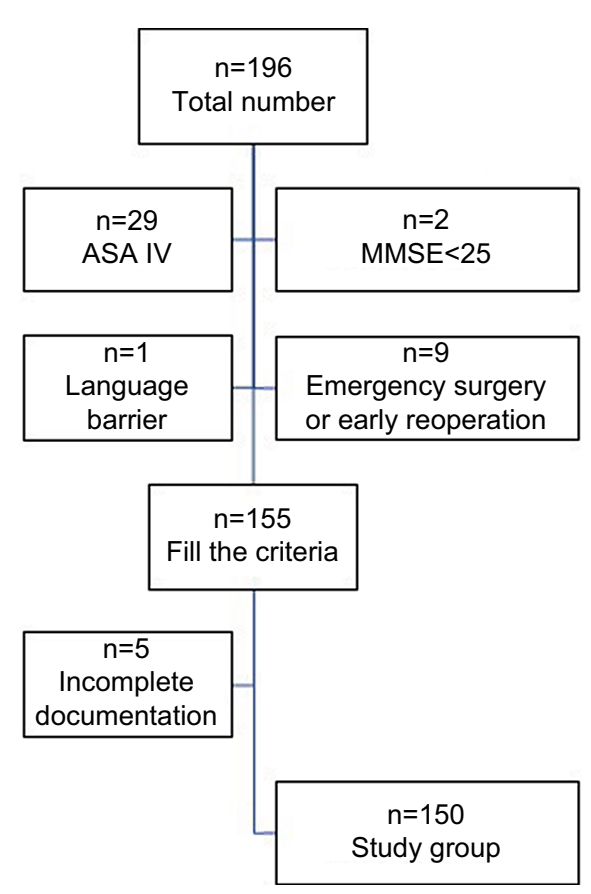

Figure I Study selection process.

Abbreviations: ASA, American Society of Anesthesiologists; MMSE, Mini-Mental State Examination. 
Table I Descriptive analysis of preoperative variables, intraoperative data, and psychological test results

\begin{tabular}{|c|c|}
\hline Variable analyzed & Overall $(n=150)$ \\
\hline \multicolumn{2}{|l|}{ Preoperative variables } \\
\hline \multicolumn{2}{|l|}{ Patients' demographic data } \\
\hline Age (years), mean [95\% Cl] & $57.23[55.26-59.21]$ \\
\hline Age groups: $18-40$ years, $n$ (\%) & $15(10.0)$ \\
\hline $4 \mathrm{I}-65$ years, $n(\%)$ & $87(58.0)$ \\
\hline$>65$ years, $n(\%)$ & $48(32.0)$ \\
\hline Male/female, $\mathrm{n}(\%)$ & $84(56.0) / 66(44.0)$ \\
\hline Educational level: I, primary school & $18(12.0)$ \\
\hline II, secondary school & $83(54.7)$ \\
\hline III, university & $50(33.3)$ \\
\hline BMI, mean $[95 \% \mathrm{Cl}]$ & 26.31 [25.69-26.92] \\
\hline ASA status: I, n (\%) & $32(21.3)$ \\
\hline II, n (\%) & $96(64.0)$ \\
\hline III, n (\%) & $20(13.7)$ \\
\hline \multicolumn{2}{|l|}{ Comorbidities } \\
\hline Cardiovascular comorbidity, n (\%) & $94(62.7)$ \\
\hline Diabetes mellitus, n (\%) & $44(29.3)$ \\
\hline Chronic renal failure, $\mathrm{n}(\%)$ & $15(10.0)$ \\
\hline COPD, n (\%) & $10(6.7)$ \\
\hline Current smoking, n (\%) & $54(36.0)$ \\
\hline Alcohol consumption, $\mathrm{n}(\%)^{\mathrm{a}}$ & $25(16.7)$ \\
\hline Previous operations (any), n (\%) & $99(34.0)$ \\
\hline Previous renal surgeries, n (\%) & $18(12.0)$ \\
\hline \multicolumn{2}{|l|}{ Preoperative pain assessment } \\
\hline $\begin{array}{l}\text { Frequent use of analgesics during the } \\
\text { previous month, } n(\%)^{\mathrm{b}}\end{array}$ & $45(30.0)$ \\
\hline Pain at the operation site, $\mathrm{n}(\%)^{\mathrm{c}}$ & $35(23.3)$ \\
\hline Pain intensity (NRS), mean [95\% Cl] & $4.03[3.81-4.43]$ \\
\hline Expectation of pain (NRS), mean [95\% Cl] & $4.97[4.58-5.36]$ \\
\hline \multicolumn{2}{|c|}{ Intraoperative/postoperative management } \\
\hline $\begin{array}{l}\text { Duration of surgery (minutes), median } \\
\text { (range) }\end{array}$ & $120(45-280)$ \\
\hline Surgical bleeding (>500 mL), $\mathrm{n}(\%)$ & $32(21.3)$ \\
\hline $\begin{array}{l}\text { Fentanyl intraoperative }(\mu \mathrm{g} / \mathrm{kg}) \text {, mean }[95 \% \\
\mathrm{Cl}]\end{array}$ & $4.97[4.79-5.15]$ \\
\hline Sevofluran $+\mathrm{N}_{2} \mathrm{O} / \mathrm{O}_{2}, \mathrm{n}(\%)^{\mathrm{d}}$ & $12 \mid(80.67)$ \\
\hline Sevofluran $+\mathrm{O}_{2} /$ air, $\mathrm{n}(\%)$ & $29(19.33)$ \\
\hline Epidural analgesia, $\mathrm{n}(\%)$ & $19(13.0)$ \\
\hline IV morphine, $\mathrm{n}(\%)$ & $27(18.0)$ \\
\hline IV tramadol, n (\%) & $104(69.0)$ \\
\hline \multicolumn{2}{|l|}{ Results of psychological tests } \\
\hline APAIS, mean $[95 \% \mathrm{Cl}]$ & $15.38[14.22-16.24]$ \\
\hline APAIS anxiety $[95 \% \mathrm{Cl}]$ & $10.36[9.56-11.15]$ \\
\hline APAIS need for information $[95 \% \mathrm{Cl}]$ & $5.09[4.63-5.54]$ \\
\hline HAM-A, mean $[95 \% \mathrm{Cl}]$ & $10.38[8.56-12.20]$ \\
\hline HAM-D, mean $[95 \% \mathrm{CI}]$ & $8.72[7.32-10.11]$ \\
\hline PCS, mean $[95 \% \mathrm{Cl}]$ & $11.7 \mid[9.50-13.91]$ \\
\hline
\end{tabular}

Notes: a'More than one unit of alcohol per day; ${ }^{\text {b}}$ Yes $=$ at least once every week, almost every day, every day. No = never, few times a month; 'Number of patients with previous pain at operation site; ${ }^{d}$ Number of patients who received $\mathrm{N}_{2} \mathrm{O}$ in anesthetic gas mixture.

Abbreviations: $\mathrm{Cl}$, confidence interval; $\mathrm{BMI}$, body mass index; ASA, American Society of Anesthesiologists; COPD, chronic obstructive pulmonary disease; APAIS, Amsterdam Preoperative Anxiety Information Scale; HAM-A, Hamilton Anxiety Rating Scale; HAM-D, Hamilton Depression Rating Scale; PCS, Pain Catastrophizing Scale; IV, intravenous; NRS, numerical rating scale. "immediate early", "early", and "late early" postoperative periods (Table 2)

"Pain at the surgical site prior to surgery", "previous renal surgeries", and "usage of analgesics during the month before surgery" were significantly correlated with pain intensity in all the three postoperative periods.

However, the strongest associations were found between pain intensity and postoperative analgesic strategy as well as preoperative psychological assessments.

Epidural analgesia correlated with pain intensity during the "immediate early" and the "early" but not the "late early" postoperative phase. This suggests that epidural infusions are most effective within the first 24 hours after nephrectomy.

In addition, all psychological variables ("anxiety" [APAIS, HAM-A], “depression” [HAM-D], “expected pain”, and "pain catastrophizing" [PCS]) were associated with postoperative pain. However, "expected pain" and "APAIS anxiety" showed the strongest correlation (Table 3 ).

Finally, a multiple linear regression analysis was performed to identify variables that predicted pain intensity in "immediate early", "early", and "late early" postoperative periods. The seven explanatory variables included into the model were those that were found to be significantly associated with postoperative pain scores (correlation coefficient $\geq 0.2$ ) in the correlation matrix at least at one time point. Regression analysis was performed in two steps (model 1 and 2, respectively) controlling for postoperative analgesia. The results of the analysis are presented in Table 4.

"Expected pain" was the only predictor for pain in the "immediate early" postoperative period. However, this effect diminished over time. Conversely, "anxiety" was most important in the "early" postoperative phase with both HAM-A and APAIS anxiety predicting patients' pain. In the "late early" phase, the psychological phenotype changed again. Now pain catastrophizing was the predominant predictor of pain intensity, along with "preoperative analgesic usage" and "APAIS anxiety".

The post hoc statistical power calculation for the seven predictors included into the regression analysis showed a power of $99.7 \%$. This was based on, the observed $R^{2}=0.194$, the sample size of 150 and an assumed type I error of $5 \%$.

\section{Discussion}

The main findings of the present study suggest that the employed postoperative analgesic strategies are quickly superseded by psychological factors as predictors of pain 


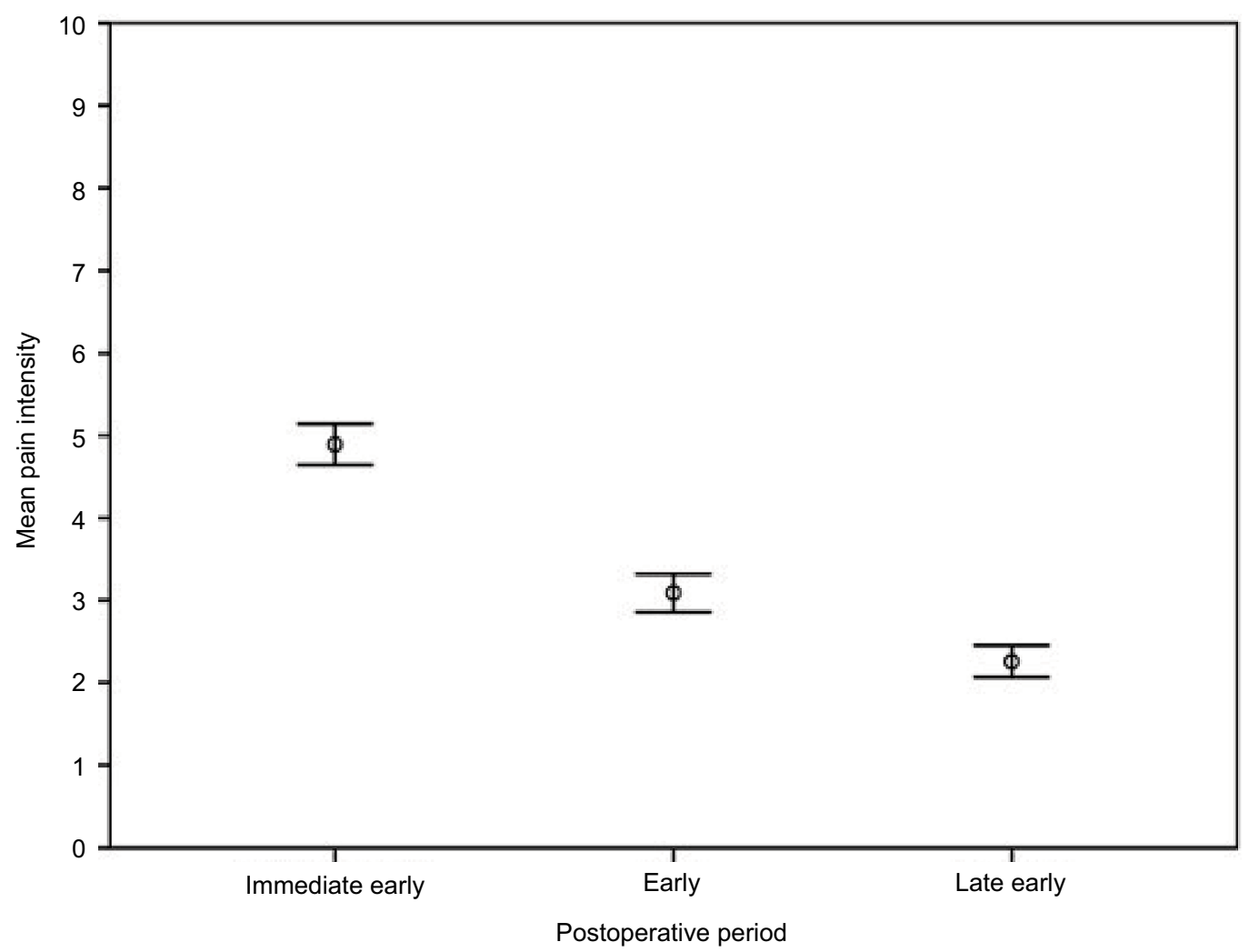

Figure 2 Mean pain intensity over time.

Notes: Mean pain intensity-NRS score; Immediate early postoperative period ( I-8 hours); early postoperative period (I 2-24 hours); late early postoperative period (48-72 hours). Error bars: $95 \% \mathrm{Cl}$.

Abbreviations: $\mathrm{Cl}$, confidence interval; NRS, numerical rating scale.

after open nephrectomy. Especially "expected pain", "anxiety", and "pain catastrophizing" were identified to influence pain experience, even when the analysis was controlled for analgesic strategy. Results further indicate the psychological phenotype changes over time.

\section{Pain intensity and analgesics strategies}

Pain intensity in the "immediate early", "early", and "late early" postoperative phases was similar in our study compared to what was reported previously after open nephrectomy. ${ }^{18}$ This suggests that our patient cohort was not different from those in other studies indicating results presented here are reliable.

Nevertheless, pain in the immediate postoperative phase (hours 1-8) was rather high, which was likely a consequence of the applied analgesic technique. This notion is supported by the finding that most patients received IV opioid-based analgesia and that their early pain was significantly higher compared to the pain experienced by patients with epidural analgesia. Previous studies have advocated the use of thoracic epidural catheters because of the superior quality of periop- erative analgesia compared with parenteral opioids in patients undergoing upper abdominal surgery. ${ }^{19}$ However, although providing good analgesia, epidural drug administrations are under scrutiny because of their potential to cause considerable adverse events. ${ }^{20}$ Busy theater schedules and insufficient number of anesthetists could also explain why a relatively great number of our patients had received IV instead of epidural analgesia. However, this is not an exclusive characteristic of our cohort. Fletcher et al, for instance, also report a low usage of epidural analgesia in their French cohort. ${ }^{21}$

In our study, although patients receiving epidural analgesia reported significantly lower pain scores during the "immediate early" postoperative period, this effect started to diminish after 12 hours. Interestingly, after 72 hours, they even reported higher scores. While the latter could be explained by the removal of epidural catheters after 48 hours, the results, nevertheless, suggest a value for epidural analgesia only within the first 12 hours. Similar to our findings, retrospective study by Winer et al conducted on 308 patients who underwent open cystectomy showed that analgesia, defined by pain scores, was significantly improved 


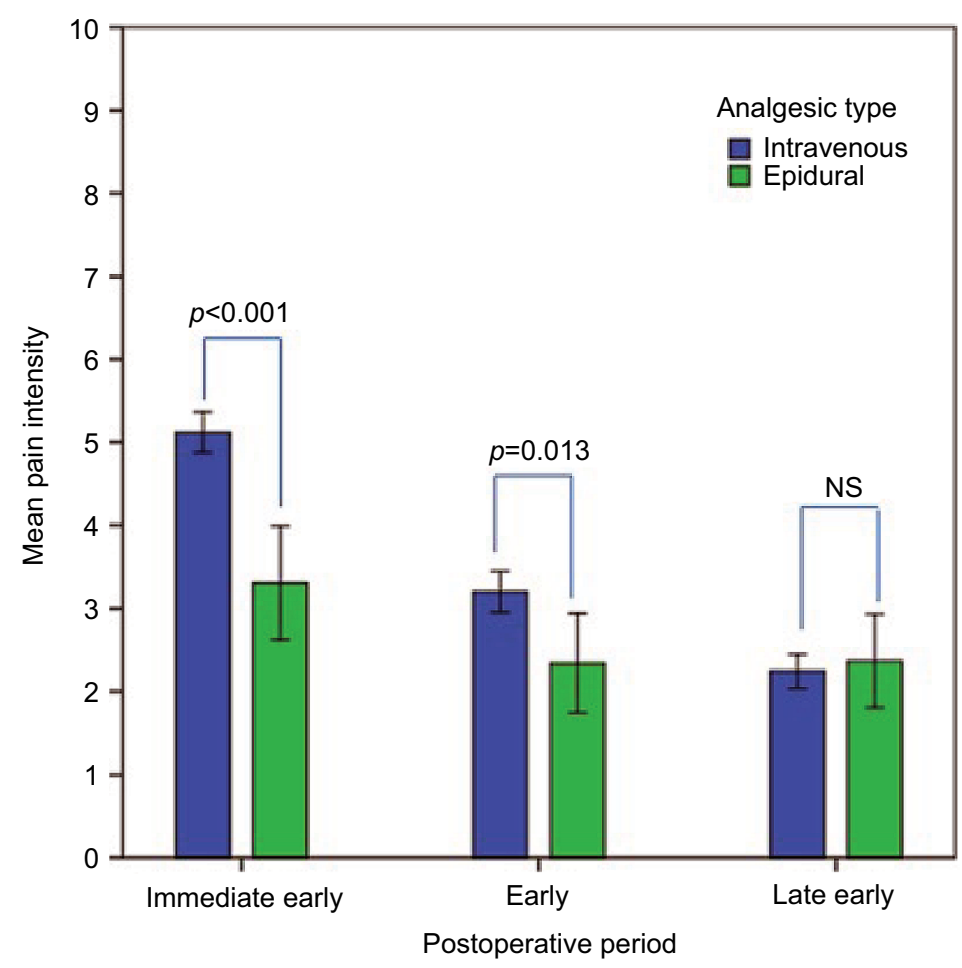

Figure 3 Mean pain intensity in epidural and intravenous analgesic group over time.

Notes: Mean pain intensity-NRS score; immediate early postoperative period (I-8 hours); early postoperative period (I2-24 hours); late early postoperative period (48-72 hours). Repeated measures ANOVA - pain intensities differed significantly in "immediate early" period $(p<0.0 \mathrm{I})$ and "early" period $(p=0.0 \mathrm{I} 3)$ but not in "late early" period. Error bars: $95 \% \mathrm{Cl}$.

Abbreviations: $\mathrm{Cl}$, confidence interval; NRS, numerical rating scale; NS, nonsignificant; ANOVA, analysis of variance.

in the Patient Control Epidural Analgesia (epidural) cohort on postoperative days 1 and 2 . But on day 3 , there was no difference in pain scores between the two groups. ${ }^{22}$

\section{Predictors of postoperative pain "Immediate early" postoperative period}

In addition to "analgesic strategy", "expected pain" was the only psychological variable in the "immediate early" period that contributed significantly to patients' pain experience in our study. This is only partially in keeping with a study by Sommer et al who found "expected pain" $>40 \mathrm{~mm}$ on a visual analog scale $(0-100 \mathrm{~mm})$ to be the most important predictor for severe postoperative pain during their 4-day observation period. ${ }^{2}$ However, Sommer et al's results were derived from a heterogeneous patient cohort, which differs from our own.

The influence of pain-specific expectations on the subjective experience of pain is well documented. Expectation was identified as one of the core mechanisms underlying placebo analgesia. ${ }^{23}$ Interestingly, pain-specific expectations not only influence pain reports but also influence the neuronal processes that underlie nociception and pain relief. A functional MRI study by Keltner et al found that pain expectation and noxious peripheral stimuli have additive effects on afferent nociceptive pathways. Using an experimental design with two levels of noxious thermal stimulation and two corresponding levels of expectancy, Keltner et al's results support the idea that expecting pain of high intensity is necessary for a maximal activation of afferent pain pathways that subsequently lead to a high level of perceived pain. ${ }^{24}$ Further, in an experimental MRI study by Koyama et al, the specific brain regions responsible for pain expectation were identified. The authors describe that pain-intensity-related brain activation grossly overlapped with expectation-related regional activation, even though these two cognitively distinctive states were separated in time. ${ }^{25}$ Finally, Svensson et al note that patients commonly expect moderate to severe pain postoperatively. Patients' actual pain experience is then frequently similar to their preoperative expectations. ${ }^{26}$ In accordance with Svensson et al, it can therefore be argued that those of our patients who had experienced pain before surgery expected more pain and had consequently higher pain scores after the operation. 
Table 2 Correlation between patients' characteristics and postoperative pain

\begin{tabular}{|c|c|c|c|c|c|c|c|c|c|c|c|c|c|}
\hline Variables & (I) & (II) & (III) & (IV) & (V) & (VI) & (VII) & (VIII) & (IX) & $(\mathbf{X})$ & $(\mathbf{X I})$ & $(X I I)$ & (XIII) \\
\hline Age (years) & 1.0 & & & & & & & & & & & & \\
\hline \multicolumn{14}{|l|}{ (I) } \\
\hline Gender & $-0.016 *$ & 1.0 & & & & & & & & & & & \\
\hline \multicolumn{14}{|l|}{ (II) } \\
\hline ASA & $0.49 * *$ & -0.10 & 1.0 & & & & & & & & & & \\
\hline \multicolumn{14}{|l|}{ (III) } \\
\hline Education & $-0.027 * *$ & 0.11 & $0.18 *$ & 1.0 & & & & & & & & & \\
\hline \multicolumn{14}{|l|}{ (IV) } \\
\hline BMI & $0.31 * *$ & $0.21 * *$ & 0.13 & -0.16 & 1.0 & & & & & & & & \\
\hline \multicolumn{14}{|l|}{ (V) } \\
\hline Previous surgeries & $0.23 * *$ & $-0.21 * *$ & $0.30 * *$ & -0.04 & -0.12 & 1.0 & & & & & & & \\
\hline \multicolumn{14}{|l|}{ (VI) } \\
\hline $\begin{array}{l}\text { Previous renal surgeries } \\
\text { (VII) }\end{array}$ & 0.3 & 0.8 & $0.19 *$ & -0.03 & -0.06 & $0.28 * *$ & 1.0 & & & & & & \\
\hline $\begin{array}{l}\text { Cardiovascular comorbidity } \\
\text { (VIII) }\end{array}$ & $0.44 * *$ & -0.16 & $0.59 * *$ & $-0.18 *$ & $0.31 * *$ & $0.24 * *$ & 0.12 & 1.0 & & & & & \\
\hline \multicolumn{14}{|l|}{ (IX) } \\
\hline Chronic renal failure & $0.24 * *$ & -0.11 & $0.20 * *$ & -0.04 & -0.05 & $0.17 *$ & 0.09 & $0.21 * *$ & 0.08 & 1.0 & & & \\
\hline \multicolumn{14}{|l|}{$(\mathbf{X})$} \\
\hline COPD comorbidity & 0.05 & $0.18 *$ & $0.22 * *$ & -0.01 & -0.03 & 0.11 & 0.15 & 0.09 & 0.12 & -0.09 & 1.0 & & \\
\hline \multicolumn{14}{|l|}{ (XI) } \\
\hline Smoking ${ }^{a}$ & -0.09 & 0.13 & -0.09 & -0.13 & -0.01 & -0.03 & 0.02 & $0.20 * *$ & -0.06 & -0.07 & 0.13 & 1.0 & \\
\hline \multicolumn{14}{|l|}{$(X I I)$} \\
\hline Alcohol use & -0.13 & $0.36 * *$ & -0.06 & -0.01 & 0.02 & -0.06 & -0.00 & -0.14 & 0.03 & -0.03 & $0.17 *$ & $0.37 * *$ & 1.0 \\
\hline \multicolumn{14}{|l|}{ (XIII) } \\
\hline NRS I-8 & -0.08 & -0.11 & -0.05 & -0.08 & 0.02 & -0.04 & 0.11 & -0.06 & 0.03 & -0.03 & 0.12 & 0.02 & -0.04 \\
\hline NRS I 2-24 & -0.00 & -0.08 & 0.03 & -0.12 & 0.07 & 0.05 & $0.18 *$ & 0.01 & 0.15 & 0.09 & 0.07 & -0.01 & 0.07 \\
\hline NRS 48-72 & 0.07 & -0.05 & 0.10 & 0.02 & -0.01 & 0.01 & 0.04 & 0.11 & 0.14 & 0.02 & 0.16 & 0.00 & 0.04 \\
\hline
\end{tabular}

Notes: (I) Age; (II) gender; (III) ASA; (IV) education; (V) BMI; (VI) previous surgeries; (VII) previous renal surgeries; (VIII) cardiovascular comorbidity; (IX) diabetes mellitus; $(\mathrm{X})$ chronic renal failure; (XI) COPD comorbidity; (XII) smoking; and (XIII) alcohol use. ${ }^{a}$ Habit of smoking $(0=$ no; $I=y e s)$; ${ }^{b}$ more than one unit of alcohol per day. ${ }^{*} p<0.05$; $* * p<0.01$.

Abbreviations: ASA, American Society of Anesthesiologists; BMI, body mass index; NRS, numerical rating scale.

\section{"Early" postoperative period}

Different to the "immediate early period", two measures of anxiety (APAIS and HAM-A) were found to be predictors of pain in the "early" postoperative period. With the importance of analgesic strategy diminishing at the same time, this likely indicates plasticity within the psychological phenotype relevant for pain after surgery.

Although a considerable proportion of patients are anxious prior to surgery, the predictive role of anxiety for postoperative pain is not fully established yet as results from studies are inconsistent so far. Differences in questionnaires, types of operations, as well as in sample sizes may account for the observed discrepancies. ${ }^{27}$ However, Ip et al in their qualitative systematic review highlighted "anxiety" as the most common predictor of postoperative pain. They found a positive correlation of different types of anxiety (trait, state anxiety, or fear of postoperative pain) with pain intensity in all the 15 studies they included. ${ }^{7}$ We therefore employed two assessment tools for "anxiety" to make results more robust. We used the HAM-A, which together with the State-Trait Anxiety Inventory (STAI) test is one of the most frequently used tools to detect anxiety. Since previous studies demonstrated a strong association between those two scales, our results are likely to be comparable..$^{28}$ Additionally, we assessed preoperative anxiety with the APAIS. As, at present, there is no consensus as to which of the existing tools is the most sensitive and specific in assessing preoperative anxiety, we used APAIS alongside HAM-A. ${ }^{29}$ Moreover, other than HAM-A, APAIS was specifically designed for use in the perioperative setting. It has also the advantage of being quicker to complete compared with other tests. Kalkman et al measured preoperative anxiety with both APAIS and STAI. They showed a greater sensitivity of APAIS compared to STAI in detecting patients at risk for high postoperative pain. APAIS was subsequently 
Table 3 Correlation between preoperative pain, intraoperative conditions, psychological variables, and postoperative pain

\begin{tabular}{|c|c|c|c|c|c|c|c|c|c|c|c|c|c|c|c|}
\hline Variables & (I) & (II) & (III) & (IV) & (V) & (VI) & (VII) & (VIII) & (IX) & $(\mathbf{X})$ & $(\mathbf{X I})$ & (XII) & (XIII) & (XIV) & $(X V)$ \\
\hline $\begin{array}{l}\text { Preop pain }^{\mathrm{a}} \\
\text { (I) }\end{array}$ & 1.0 & & & & & & & & & & & & & & \\
\hline $\begin{array}{l}\text { Chronic pain } \\
\text { (II) }\end{array}$ & $0.29 * *$ & 1.0 & & & & & & & & & & & & & \\
\hline $\begin{array}{l}\text { Preop analgesics } \\
\text { usagec (III) }^{\text {(II) }}\end{array}$ & $0.28 * *$ & $0.58 * *$ & 1.0 & & & & & & & & & & & & \\
\hline $\begin{array}{l}\text { Expected pain } \\
\text { (IV) }\end{array}$ & $0.19 *$ & 0.13 & $0.19 *$ & 1.0 & & & & & & & & & & & \\
\hline $\begin{array}{l}\text { Intraop fentanyl } \\
\text { use }^{d}(V)\end{array}$ & -0.09 & -0.07 & -0.01 & -0.05 & 1.0 & & & & & & & & & & \\
\hline $\begin{array}{l}\mathrm{N}_{2} \mathrm{O} / \mathrm{O}_{2}{ }^{\mathrm{e}} \\
(\mathrm{VI})\end{array}$ & -0.09 & 0.05 & 0.08 & 0.05 & 0.04 & 1.0 & & & & & & & & & \\
\hline Duration $^{\mathrm{f}}$ (VII) & 0.03 & -0.08 & 0.05 & 0.07 & -0.01 & -0.02 & 1.0 & & & & & & & & \\
\hline $\begin{array}{l}\text { Blood loss' } \\
\text { (VIII) }\end{array}$ & 0.12 & -0.05 & 0.08 & 0.04 & -0.15 & -0.00 & $0.39 * *$ & 1.0 & & & & & & & \\
\hline $\begin{array}{l}\text { APAIS total } \\
\text { (IX) }\end{array}$ & -0.03 & -0.05 & 0.04 & $0.26 * *$ & 0.12 & 0.00 & -0.08 & -0.02 & 1.0 & & & & & & \\
\hline $\begin{array}{l}\text { APAIS anxiety } \\
\text { (X) }\end{array}$ & -0.00 & -0.05 & 0.04 & $0.26 * *$ & 0.15 & 0.01 & -0.08 & -0.03 & $0.94 * *$ & 1.0 & & & & & \\
\hline $\begin{array}{l}\text { APAIS info } \\
\text { (XI) }\end{array}$ & 0.00 & -0.03 & 0.06 & $0.26 * *$ & 0.06 & 0.03 & -0.05 & 0.02 & $0.86 * *$ & $0.70 * *$ & 1.0 & & & & \\
\hline $\begin{array}{l}\text { PCS } \\
(X I I)\end{array}$ & $0.21 *$ & $0.30 * *$ & $0.24 * *$ & $0.23 * *$ & 0.17 & 0.04 & -0.13 & -0.11 & $0.50 * *$ & $0.50 * *$ & $0.43 * *$ & 1.0 & & & \\
\hline $\begin{array}{l}\text { HAM-A } \\
\text { (XIII) }\end{array}$ & 0.12 & $0.17 *$ & $0.24 * *$ & 0.13 & 0.01 & -0.02 & 0.02 & 0.12 & $0.48 * *$ & $0.47 * *$ & $0.40 * *$ & $0.47 * *$ & 1.0 & & \\
\hline $\begin{array}{l}\text { HAM-D } \\
\text { (XIV) }\end{array}$ & 0.08 & $0.32 * *$ & $0.30 * *$ & 0.15 & 0.08 & 0.06 & -0.02 & 0.03 & $0.27 * *$ & $0.27 * *$ & $0.23 * *$ & $0.55 * *$ & $0.67 * *$ & 1.0 & \\
\hline $\begin{array}{l}\text { Epidural }^{\mathrm{h}} \\
(\mathrm{XV})\end{array}$ & $-0.17 *$ & $-0.20 *$ & -0.12 & $0.28 * *$ & 0.01 & -0.07 & 0.08 & -0.07 & -0.13 & $-0.18 *$ & -0.09 & -0.14 & -0.14 & -0.10 & 1.0 \\
\hline NRS I-8 & $0.19 *$ & 0.13 & $0.21 *$ & $0.42 * *$ & -0.14 & 0.07 & 0.07 & 0.05 & $0.26 * *$ & $0.26 * *$ & $0.21 * *$ & $0.17 *$ & $0.19 *$ & 0.13 & $-0.4 I * *$ \\
\hline NRS I 2-24 & 0.03 & 0.09 & $0.18 *$ & $0.27 * *$ & 0.00 & 0.04 & 0.01 & 0.08 & $0.35 * *$ & $0.40 * *$ & $0.22 * *$ & $0.19 *$ & $0.29 * *$ & $0.17 *$ & $-0.21 * *$ \\
\hline NRS 48-72 & 0.08 & 0.14 & $0.23 * *$ & 0.13 & 0.00 & 0.15 & -0.03 & -0.03 & $0.27 * *$ & $0.31 * *$ & 0.15 & $0.26 * *$ & $0.20 *$ & 0.13 & 0.06 \\
\hline
\end{tabular}

Notes: (I) Preoperative pain; (II) chronic pain; (III) preoperative analgesic usage; (IV) expected pain; (V) intraop fentanyl use; (VI) $\mathrm{N}_{2} \mathrm{O} / \mathrm{O}_{2}$; (VII) duration; (VIII) blood loss; (IX)

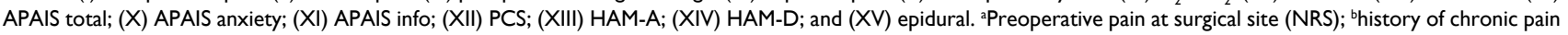
in last 3 months; 'the use of analgesic during the last month before surgery (Yes = at least once every week, almost every day, every day; No = never, few times a month);

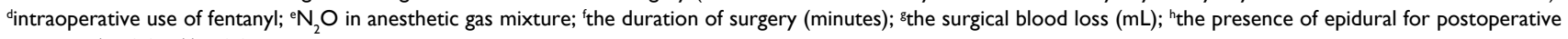
analgesia. $* p<0.05 ; * *<0.01$.

Abbreviations: APAIS, Amsterdam Preoperative Anxiety Information Score; PCS, Pain Catastrophizing Scale; HAM-A, Hamilton Anxiety Rating Scale; HAM-D, Hamilton Depression Scale; NRS, numerical rating scale.

included into the nomogram developed by Kalkman et al to identify patients at risk for moderate to severe postoperative pain. ${ }^{30}$ As both HAM-A and APAIS were predictors of pain in the "early" postoperative period, "anxiety" likely is important for pain after open nephrectomy.

\section{"Late early" postoperative period}

The importance of anxiety for postoperative pain was also observed in the "late early" period after surgery. Yet, similar to Kalkman et al's study, APAIS was more sensitive to detect anxiety than HAM-A, which was not found to predict postoperative pain anymore. ${ }^{30}$ As "catastrophizing" also predicted pain after surgery in this phase, all three postsurgical periods showed distinct psychological phenotypes. While "analgesic strategy" had lost its predictive value, these data suggest that psychological mechanisms are becoming increasingly more important after surgery as time passes. Future analgesic strategies should take this into consideration and may employ psychological therapies as a part of a postoperative routine. ${ }^{31}$

Catastrophizing, according to recent findings, is a psychological factor that has a strong relationship with the severity of postoperative pain. ${ }^{32}$ High preoperative catastrophizing scores tend to predict severe postsurgical pain, independent of anxiety, and/or depression. ${ }^{33}$ In our study, catastrophizing became a significant predictor on day 2 . This agrees with the results of Sommer et al and Strulov et al. They both reported catastrophizing predicted pain on the second postoperative day, but not on the first. ${ }^{2,34}$ Conversely, Pavlin et al, who also reported an association between pain and catastrophizing, described this condition for postoperative day 7, but not for 


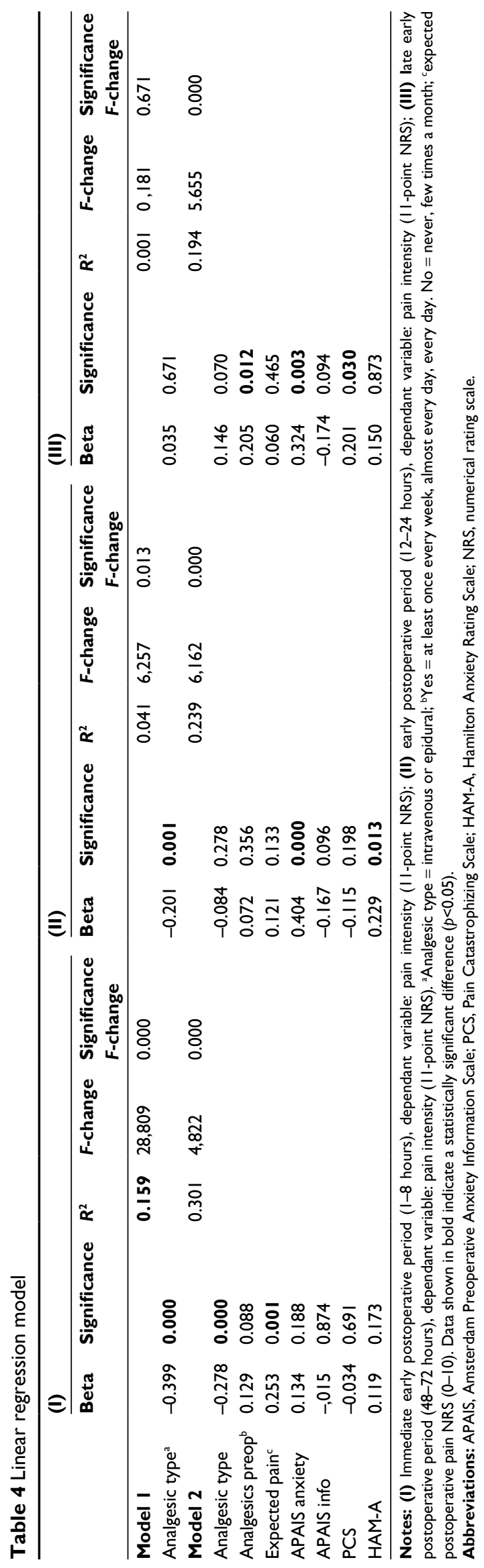

the first 24 or 48 hours. They speculated that during the first day(s) after surgery when pain was more severe, patients engaged only in limited physical activity. However, when they became more active, catastrophizing was unmasked. ${ }^{35}$ Although an interesting idea, we think more likely that if pain persists until 48 hours after surgery, patients may view this as "complication" to their recovery and subsequently activate psychological mechanisms in keeping with "catastrophizing". This is supported by evidence showing an excessive focus on pain sensation is a central feature of catastrophizing. ${ }^{36}$ Furthermore, even though pain expectancy is strongly linked to "catastrophizing", both are nevertheless viewed as unique psychological variables. ${ }^{36}$ That was likely the case in our study too. Both "expected pain" and "catastrophizing" were independent predictors of pain, albeit in two different postoperative periods. Future studies should further investigate the intricate relationship between "expected pain" and "catastrophizing". For instance, not only the magnitude of "expected pain" but also how long patients think it might last should be examined.

"Preoperative analgesic use" was found to be an independent predictor of pain in the "late early" period as well. This is not surprising as nearly one-third of patients in this study were regularly using non-opioid analgesics. Aubrun et al also reported the predictive value of preoperative analgesic therapy on postoperative pain, thus confirming our results. ${ }^{37}$ Even though more studies investigated the role of preoperative pain intensity rather than analgesic consumption on postoperative pain, we decided to include both. This is based on the idea that analgesic consumption during the month prior to surgery represents overall pain and suffering more accurately than pain intensity. However, more research is warranted to determine under what condition one variable might be preferable over the other.

\section{Additional variables}

Contrary to previous research, our study could not confirm a predictive role for depression, age, or gender for the intensity of postoperative pain. Nevertheless, this is in keeping with recent evidence. Although some studies support a positive association between depressive symptoms and the magnitude of pain,,$^{38}$ others have failed to show such a relationship. ${ }^{18}$ Similar inconsistencies have been observed with age and gender as well. For instance, for some authors age negatively correlates with pain, meaning younger patients experience more pain than those over 60 years of age.$^{39}$ However, this is not universally accepted. ${ }^{40}$ When analyzing pain trajectories, Tighe et al found that older patients, while starting with a lower postoperative pain, showed slower rates of pain resolution. ${ }^{41}$ 
The possible influence of gender on pain and analgesic consumption has become a topic of considerable scientific and clinical interest, especially in the last $10-15$ years. ${ }^{42}$ However, a recent large retrospective study has failed to show an effect of gender on postoperative pain after integumentary, musculoskeletal, pulmonary, and urinary surgeries. ${ }^{41}$

\section{Study limitations}

In this study, we assessed pain intensity employing an 11-point NRS. Although magnitude is an important characteristic of pain, it is unlikely to represent all aspects of an individual's pain experience. This is supported here by the finding that the applied statistical model could only explain $19 \%-30 \%$ of variability within the data. However, NRS is an accepted tool in clinical practice and research, providing a reliable albeit incomplete assessment of patients' pain. ${ }^{16}$

This study could be further criticized for choosing predictive variables that do not explain more variability. However, our model included a carefully chosen set of variables, which had a well-documented predictive impact on pain in previous studies. Since they were also significantly associated with pain in the correlation matrix produced here, our results are most likely reliable.

Finally, because observational studies are increasingly collecting data from multiple sites, the single-center nature of our study might be viewed as a limitation. ${ }^{4}$ We nevertheless think through the employment of a well-defined homogenous patient cohort, the results of our work add considerably to the understanding of perioperative pain.

\section{Conclusion}

After open nephrectomy, epidural analgesia conveys a clear advantage only within the first 24 hours after surgery compared to systemic opioid administrations. A continued use afterward is hence unlikely to result in improved pain relief. In addition, as the psychological phenotype of patients also changes distinctively in the early (first 3 days) postoperative period, the importance of psychological variables as predictors of postoperative pain increases. They even surpass the predictive value of the analgesic strategy employed. As a consequence, modern postoperative pain management should include plans to monitor and treat patients' pain enhancing psychological conditions.

\section{Acknowledgment}

We would like to thank the nursing staff in the ICU (Urology Clinic, Clinical Centre of Serbia) for their help and support.

\section{Disclosure}

The authors report no conflicts of interest in this work.

\section{References}

1. Nielsen PR, Rudin $\AA$, Werner MU. Prediction of postoperative pain. Curr Anaesth Crit Care. 2007;18:157-165.

2. Sommer M, de Rijke JM, van Kleef M, et al. Predictors of acute postoperative pain after elective surgery. Clin J Pain. 2010;26: 87-94.

3. Sommer M, Geurts JW, Stessel B, et al. Prevalence and predictors of postoperative pain after ear, nose, and throat surgery. Arch Otolaryngol Head Neck Surg. 2009;135:124-130.

4. Gerbershagen HJ, Aduckathil S, van Wijck AJ, Peelen LM, Kalkman CJ, Meissner W. Pain intensity on the first day after surgery. A prospective cohort study comparing 179 surgical procedures. Anesthesiology. 2013;118:934-144.

5. Stamer UM, Stüber F. Genetic factors in pain and its treatment. Curr Opin Anesthesiol. 2007;20:478-484.

6. Gerbershagen HJ, Pogatzki-Zahn E, Aduckathil S, et al. Procedurespecific risk factor analysis for the development of severe postoperative pain. Anesthesiology. 2014;120:1237-1245.

7. Ip HY, Abrishami A, Peng PW, Wong J, Chung F. Predictors of postoperative pain and analgesic consumption: a qualitative systematic review. Anesthesiology. 2009;111:657-677.

8. Ruscheweyh R, Viehoff A, Tio J, Pogatzki-Zahn EM. Psychophysical and psychological predictors of acute pain after breast surgery differ in patients with and without pre-existing chronic pain. Pain. 2017;158:1030-1038.

9. Pinto PR, McIntyre T, Fonseca C, Almeida A, Araújo-Soares V. Preand post-surgical factors that predict the provision of rescue analgesia following hysterectomy. Eur J Pain. 2013;17:423-433.

10. Folstein MF, Folstein SE, McHugh PR. "Mini-mental state": a practical method for grading the cognitive state of patients for the clinician. J Psychiatr Res. 1975;12:189-198.

11. Moerman N, van Dam FS, Muller MJ, Oosting H. The Amsterdam preoperative anxiety and information scale (APAIS). Anesth Analg. 1996;82:445-451

12. Hamilton M. The assessment of anxiety states by rating. $\mathrm{Br} J \mathrm{Med}$ Psychol. 1959;32:50-55.

13. Hamilton M. A rating scale for depression. J Neurol Neurosurg Psychiatry. 1960;23:56-62.

14. Sullivan M, Bishop S, Pivik J. The pain catastrophizing scale: development and validation. Psychol Assess. 1995;7:524-532.

15. Osman A, Barrios FX, Gutierrez PM, Kopper BA, Merrifield T, Grittmann L. The Pain Catastrophizing Scale: further psychometric evaluation with adult samples. J Behav Med. 2000;23:351-365.

16. Breivik H, Borchgrevink PC, Allen SM, et al. Assessment of pain. $B r$ J Anaesth. 2008; 101:17-24.

17. Hjermstad MJ, Fayers PM, Haugen DF, et al. European Palliative Care Research Collaborative. Studies comparing Numerical Rating Scales, Verbal Rating Scales, and Visual Analogue Scales for assessment of pain intensity in adults: a systematic literature review. J Pain Symptom Manage. 2011;41:1073-1093.

18. Gerbershagen HJ, Dagtekin O, Rothe T, et al. Risk factors for acute and chronic postoperative pain in patients with benign and malignant renal disease after nephrectomy. Eur J Pain. 2009;13:853-860.

19. Manion SC, Brennan TJ. Thoracic epidural analgesia and acute pain management. Anesthesiology. 2011;115:181-188.

20. Capdevila X, Moulard S, Plasse C, et al. Effectiveness of epidural analgesia, continuous surgical site analgesia, and patient-controlled analgesic morphine for postoperative pain management and hyperalgesia, rehabilitation, and health-related quality of life after open nephrectomy: a prospective, randomized, controlled study. Anesth Analg. 2017;124:336-345. 
21. Fletcher D, Fermanian C, Mardaye A, Aegerter P. A patient-based national survey on postoperative pain management in France reveals significant achievements and persistent challenges. Pain. 2008;137: $441-451$.

22. Winer AG, Sfakianos JP, Puttanniah VG, et al. Comparison of perioperative outcomes for epidural versus intravenous patient-controlled analgesia after radical cystectomy. Reg Anesth Pain Med. 2015;40:239.

23. Hanssen MM, Linda M, VancleefG, Johan W, Vlaeyen S, Peters ML. More optimism, less pain! The influence of generalized and pain-specific expectations on experienced cold-pressor pain. J Behave Med. 2014;37:47.

24. Keltner JR, Furst A, Fan C, Redfern R, Inglis B, Fields HL. Isolating the modulatory effect of expectation on pain transmission: a functional magnetic resonance imaging study. J Neurosci. 2006;26:4437-4443.

25. Koyama T, McHaffie JG, Laurienti PJ, Coghill RC. The subjective experience of pain: where expectations become reality. Proc Nati Acad Sci USA. 2005;102:12950-12955.

26. Svensson I, Sjöström B, Haljamäe H. Influence of expectations and actual pain experiences on satisfaction with postoperative pain management. Eur J Pain. 2001;5:125-133.

27. Granot M, Ferber SG. The roles of pain catastrophizing and anxiety in the prediction of postoperative pain intensity. Clin J Pain. 2005;21:439-445.

28. Donzuso G, Cerasa A, Gioia MC, Caracciolo M, Quattrone A. The neuroanatomical correlates of anxiety in a healthy population: differences between the State-Trait Anxiety Inventory and the Hamilton Anxiety Rating Scale. Brain Behav. 2014;4:504-514.

29. Wiles MD, Mamdani J, Pullman M, Andrzejowski JC. A randomised controlled trial examining the effect of acupuncture at the EX-HN3 (Yintang) point on pre-operative anxiety levels in neurosurgical patients. Anaesthesia. 2017;72:335-342.

30. Kalkman CJ, Visser K, Moen J, Bonsel GJ, Grobbee DE, Moons KG. Preoperative prediction of severe postoperative pain. Pain. 2003;105:415-423.
31. Childs SR, Casely EM, Kuehler BM, et al. The clinical psychologist and the management of inpatient pain: a small case series. Neuropsychiatr Dis Treat. 2014;10:2291.

32. Sobol-Kwapinska M, Bąbel P, Plotek W, Stelcer B. Psychological correlates of acute postsurgical pain: a systematic review and meta-analysis. Eur J Pain. 2016;20:1573-1586.

33. Khan RS, Skapinakis P, Ahmed K, et al. The association between preoperative pain catastrophizing and postoperative pain intensity in cardiac surgery patients. Pain Med. 2012;13:820-827.

34. Strulov L, Zimmer EZ, Granot M, Tamir A, Jakobi P, Lowenstein L. Pain catastrophizing, response to experimental heat stimuli, and postcaesarean section pain. J Pain. 2007;8:273-279.

35. Pavlin DJ, Sullivan MJ, Freund PR, Roesen K. Catastrophizing: a risk factor for postsurgical pain. Clin J Pain. 2005;21:83-90.

36. Sullivan MJ, Rodgers WM, Kirsch I. Catastrophizing, depression and expectancies for pain and emotional distress. Pain. 2001;91:147-154.

37. Aubrun F, Valade N, Coriat P, Riou B. Predictive factors of severe postoperative pain in the postanesthesia care unit. Anesth Analg. 2008;106:1535-1541.

38. Pinto PR, McIntyre T, Araújo-Soares V, Costa P, Almeida A. Differential predictors of acute post-surgical pain intensity after abdominal hysterectomy and major joint arthroplasty. Ann Behav Med. 2015;49:384-397.

39. Macintyre PE, Jarvis DA. Age is the best predictor of postoperative morphine requirements. Pain. 1996;64:357-364.

40. Chia YY, Chow LH, Hung CC, Liu K, Ger LP, Wang PN. Gender and pain upon movement are associated with the requirements for postoperative patient-controlled analgesia: a prospective survey of 2,298 Chinese patients. Can J Anaesth. 2002;49:249-255.

41. Tighe PJ, Le-Wendling LT, Patel A, Zou B, Fillingim RB. Clinically derived early postoperative pain trajectories differ by age, sex, and type of surgery. Pain. 2015;156:609.

42. Bartley EJ, Fillingim RB. Sex differences in pain: a brief history of clinical and experimental findings. Br J Anaesth. 2013;111:52-58.
Journal of Pain Research

\section{Publish your work in this journal}

The Journal of Pain Research is an international, peer reviewed, open access, online journal that welcomes laboratory and clinical findings in the fields of pain research and the prevention and management of pain. Original research, reviews, symposium reports, hypothesis formation and commentaries are all considered for publication.

\section{Dovepress}

The manuscript management system is completely online and includes a very quick and fair peer-review system, which is all easy to use. Visit http://www.dovepress.com/testimonials.php to read real quotes from published authors. 